neoplasias urogenitales masculinas, pudiendo aumentar hasta el $10 \%$ según los hábitos higiénicos de la población ${ }^{1}$.

Se han descrito aproximadamente 300 casos de tumores metastásicos de pene en la literatura médica internacional ${ }^{2}$. Las metástasis se asientan principalmente en los cuerpos cavernosos, no habiéndose descrito previamente casos de metástasis a nivel del cuerpo esponjoso como en nuestro caso. La mayoría de los autores coinciden en que la presencia de este tipo de metástasis corresponde a un estado muy avanzado de la enfermedad primaria, siendo la supervivencia muy limitada tras su aparición, que no suele ser superior a un año ${ }^{3}$.

Los tumores primarios tienen su origen aproximadamente en un $75 \%$ en los órganos pélvicos, principalmente la próstata, la vejiga ${ }^{4}$ aunque también en el tubo digestivo. El otro $25 \%$ corresponde a otros orígenes extrapélvicos (el riñón, el pulmón, el estómago o los supraglóticos) ${ }^{4}$. Sólo han sido descritos dos casos de metástasis de origen esofágico, asentándose ambas en los cuerpos cavernosos ${ }^{10}$.

En cuanto a los síntomas con los que debutan estos pacientes, estos son (en orden de frecuencia) sensación de masa $(30 \%)$, priapismo maligno $(20 \%)$, retención aguda de orina, lesiones ulcerativas, edema o gangrena ${ }^{4,5}$. En nuestro caso, los síntomas comprendían semierección y síntomas del tracto urinario inferior.

Con respecto a las pruebas de imagen, el mejor método diagnóstico es la RM, ya que ha demostrado su utilidad para determinar la extensión del tumor a nivel de la albugínea o la uretra ${ }^{6}$. Esto es debido a la superioridad de la RM frente a la TC o a la ECO en la diferenciación de tejidos blandos. En nuestro paciente, la RM nos permitió conocer con exactitud la extensión de la lesión. El diagnóstico definitivo es anatomopatológico.

Estas lesiones se pueden tratar con exéresis de la lesión o el legrado de los cuerpos cavernosos en caso de nódulos aislados. Otras opciones son la penectomía parcial, en casos de lesiones solitarias o localizadas en el extremo distal del pene, y penectomía total y emasculación si las lesiones son más extensas o hay invasión proximal de los cuerpos cavernosos ${ }^{7}$. Aparte, en determinados casos en los que el dolor es intratable, se puede proceder a la sección de los nervios dorsales ${ }^{8}$. En casos específicos de pacientes jóvenes, con buen estado general y quimiosensibilidad del tumor, deben intentarse esquemas de quimioterapia de forma paliativa9 ${ }^{9}$ La radioterapia no es una opción de tratamiento inicial, aunque puede ser una alternativa de forma paliativa en pacientes como el que presentamos. No obstante, las opciones más aceptadas son la actitud expectante y la biopsia o la exéresis de la lesión debido al mal pronóstico que plantea la presencia de metástasis peneana como manifestación de su tumor primario ${ }^{3,10}$.

B I B L I O G R A F Í A

1. Solsona E, Algaba F, Horenblas S, Pizzocaro G, Windahl T. European Association of Urology EAU Guidelines on Penile Cancer. Eur Urol. 2004;46:1-8.

2. Alonso Gorrea M, Guillén Navarro M, Tramoyeres Celma A, Rodríguez Hernández JH, Ferrutxe Frau J, Puig Giró R. Metastatic tumors of the penis. Arch Esp Urol. 1980;33:131-42.

3. Pellicé i Vilalta C. Side-effects in metastasis of penis. Succinct revision of Spanish urologic literature (period: 1980-2005). Actas Urol Esp. 2006;30:962-4.

4. Senkul T, Karademir K, Silit E, Ieri C, Erden D, Balolu H. Penile metastasis of prostatic adenocarcinoma. Int J Urol. 2002;9:597-8.

5. Belville WD, Cohen JA. Secondary penile malignancies: The spectrum of presentation. J Surg Oncol. 1992;51:134-7.

6. Kendi T, Batislam E, Basar MM, Yilmaz E, Altinok D, Basar H. Magnetic resonance imaging (MRI) in penile metastases of extragenitourinary cancers. Int Urol Nephrol. 2006;38:105-9.

7. Mukamel E, Farrer J, Smith RB, DeKernion JB. Metastasic carcinoma for penis: When is total penectomy indicated? Urology. 1987;29:15-8.

8. Hill JT, Khalid MA. Penile denervation. Br J Urol. 1988;61:167.

9. Preis E, Jakse G. Options in palliative therapy for penile cancer. Urologe A. 2007;46:49-53.

10. López M, Viguri A, Rosa J, Peña P. Metástasis peneana como primera manifestación de un carcinoma esofágico. Actas Urol Esp. 2009;33:318-20.

E. Morán Pascual*, C. Di Capua Sacoto, A.M. Soto Poveda, M.A. Bonillo García, P. Bahílo Mateu y F. Jiménez Cruz

Servicio de Urología, Hospital Universitario La Fe, Valencia, España

*Autor para correspondencia.

Correo electrónico: averquetedigo@hotmail.com

(E. Morán Pascual).

\title{
Hemangioma cavernoso vesical causante de hematuria en un niño
}

\section{Bladder cavernous hemangioma as a cause of hematuria in a child}

\section{Sr. Director:}

Presentamos el caso de un paciente varón de 9 años, sin antecedentes médicos o quirúrgicos de interés, remitido desde otro centro, donde fue estudiado por hematuria macroscópica asintomática de 20 días de evolución acompañada ocasionalmente de pequeños coágulos. No presentó antecedentes de traumatismo, infecciosos ni alteraciones de 


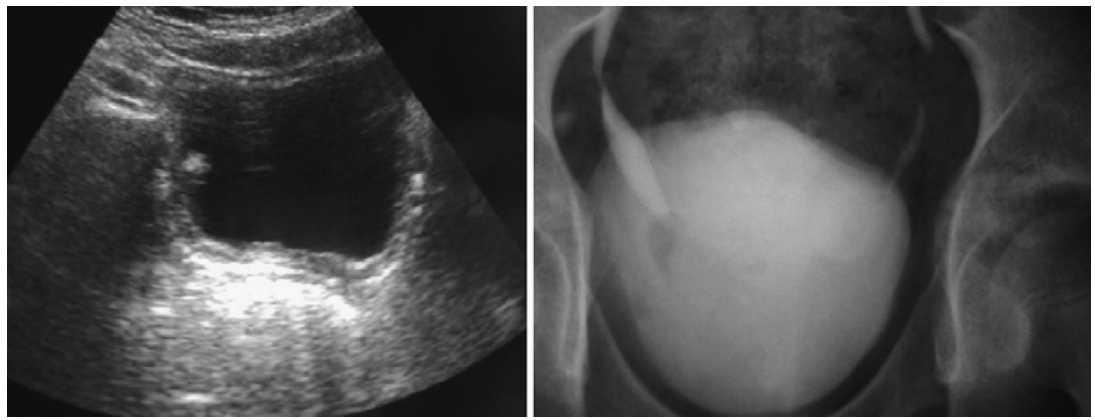

Figura 1 - Imagen del tumor vesical obtenida mediante ultrasonidos y el defecto de depleción en la cara lateral derecha observado en la urografía intravenosa.

la coagulación. En el centro de procedencia habían descartado patología renal. La ecografía realizada mostraba unos riñones con una morfometría, una función y una diferenciación corticomedular dentro de la normalidad, sin evidenciar nefrolitiasis ni ectasia. En la cara lateral derecha vesical se observa una imagen ecogénica sin sombra posterior dependiente de la pared, de aproximadamente $8 \mathrm{~mm}$ de diámetro, compatible con un tumor vesical, correspondiendo al defecto de repleción que se apareció en la urografía intravenosa en la misma zona (fig. 1).

En la exploración clínica no se observaron manifestaciones referentes a vasculopatías. La palpación abdominal y de fosas renales no evidenció zonas dolorosas ni megalias. El hemograma no reflejó anemia ni leucocitosis. La función renal, los patrones de coagulación y los reactantes de fase aguda presentaron valores dentro de la normalidad. El estudio inmunológico no presentó alteraciones: las inmunoglobulina (Ig) G, IgA e IgM, los factores del complemento C3 y C4 así como los anticuerpos ANA y anti-ADN estaban dentro de los valores normales. Las pruebas Mantoux y de frotis faríngeo fueron negativas.

Ante la sospecha de tumor vesical se procedió a la exploración endoscópica bajo anestesia general. En la cistoscoscopia no se observaron zonas de estenosis uretral. El verum montanum y el cuello vesical presentaron características normales. Se identificaron ambos meatos ureterales en situación ortotópica y de morfología normal. En la cara lateral derecha se observó dicha tumoración con sangrado activo, de $1 \mathrm{~cm}$ de diámetro aproximado, pediculada, vesicular, con un nivel de líquido hemorrágico que se resecó mediante electrocoagulación (fig. 2).

El postoperatorio fue favorable, no fue necesario instaurar lavado vesical continuo ya que no se produjo hematuria macroscópica. La sonda vesical permaneció $12 \mathrm{~h}$ y el paciente fue dado de alta a las $24 \mathrm{~h}$ tras la intervención. El diagnóstico anatomopatológico reveló que la lesión se trataba de hemangioma de histología cavernosa. El control clínico y ecográfico al mes y a los 6 meses tras la cirugía fue satisfactorio, no presentando ni hematuria ni sintomatología del tracto urinario inferior ni recidiva tumoral.

El hemangioma es considerado un tumor mesenquimatoso benigno. Su origen es congénito, ya que crece a partir de células madre embrionarias de la estirpe angioblástica ${ }^{1-3}$. Aunque es un tumor que puede aparecer a cualquier edad, como entidad única en el niño es muy raro, ya que la mayor

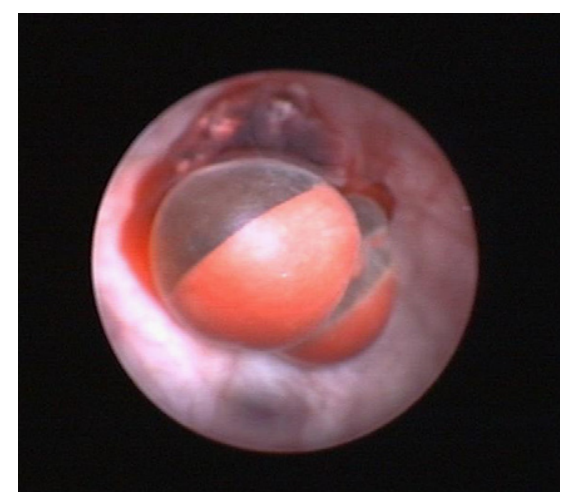

Figura 2 - Aspecto macroscópico del hemangioma vesical. Vesículas con un nivel hemorrágico evidente y sangrado activo en la base.

parte de los casos publicados se engloban dentro de síndromes cavernosos congénitos, como el síndrome de Sturge-Weber o el de Klippel-Trenaunay-Weber ${ }^{4}$.

El síntoma más común es la hematuria macroscópica, pero también puede presentarse como disfunción del vaciado vesical o dolor abdominal ${ }^{1-4}$.

En el diagnóstico macroscópico suele describirse como una masa sésil, violácea y elevada ${ }^{2}$. Rara vez aparece como formaciones vesiculares hemorrágicas pediculadas, a diferencia del caso que presentamos. La confirmación diagnóstica es mediante biopsia. El diagnóstico microscópico lo diferencia de la cistitis polipoide por la ausencia en el hemangioma cavernoso de células inflamatorias, además de observar una proliferación vascular sin atipias celulares ${ }^{2}$. Aunque en un $34 \%$ de los casos de hematuria macroscópica en el niño no se encuentra patología alguna y además las implicaciones son diferentes a las del adulto, no hay que olvidar el diagnóstico diferencial con neoformaciones vesicales o del resto de la vía urinaria como etiología de esta ${ }^{5,6}$.

Por todo esto es muy importante saber cómo orientar al paciente en la clínica en cuanto a la solicitud de pruebas complementarias y el tratamiento, ya que es una patología poco frecuente $y$, como ocurre en otras entidades urológicas en el niño como la uretrorragia, la falta de consenso en la literatura médica puede dar lugar a exploraciones innecesarias, por lo que hay que ser lo menos agresivo posible, pero no por esto prolongar la realización de pruebas invasivas 
endourológicas si se sospecha una neoformación como posible causante de la hematuria ${ }^{2,7,8}$.

Pensamos que ante una hematuria en el niño, al igual que en el adulto, la ecografía del tracto urinario debe ser la primera prueba de imagen por realizar para descartar litiasis, defectos morfológicos o neoformaciones. Ante una imagen tumoral menor o igual a $3 \mathrm{~cm}$, la exploración endoscópica, y la resección para su confirmación diagnóstica en el mismo acto, es la opción terapéutica idónea para evitar con esto una anestesia posterior. Puede ser utilizada tanto la electrocoagulación como la fulguración con láser ${ }^{1,2,7,8}$.

B I B L I O G R A F Í A

1. Fernándes ET, Manivel JC, Reinberg Y. Hematuria in a newborn infant caused by bladder hemangioma. Urology. 1996;47:412-5.

2. Cheng L, Nascimento AG, Neumann RM, Nehra A, Cheville JC, Ramnani DM, et al. Hemangioma of the urinary bladder. Cancer. 1999;86:497-504.

3. Martin Martín S, Muller Arteaga C, Gonzalo Rodríguez V, García Lagarto E, Egea Camacho J, Fernández del Busto E. Hemangioma vesical. Actas Urol Esp. 2007;31:1172-4.
4. Ikeda T, Shimamoto K, Tanji N, Ohoka H, Nishio S, Yokohama M, et al. Cavernous hemangioma of the urinary bladder in an 8-yearold child. Int J Urol. 2004;11:429-31.

5. Greenfield SP, Williot P, Kaplan D. Gross hematuria in children: A ten year review. Urology. 2007;69:166-9.

6. Domínguez Hinarejos C, Bonillo García MA, Alapont Alacreo JM, Serrano Durbá A, Estornell Moragues F, García Ibarra F. Valoración de la uretrorragia en el niño. Actas Urol Esp. 2007;31:29-32.

7. Bromage SJ, Chan L, Collins RL. Ultrasound guided location and resection of a suburothelial cavernous hemangioma of the bladder. Br J Radiol. 2007;80:e113-4.

8. Serrano A, Domínguez C. Transitional cell carcinoma of the bladder in children. Scand J Urol Nephrol. 1999;33:73-6.

J.A. March Villalba*, C. Domínguez Hinarejos, A. Serrano Durbá y F. García Ibarra

Servicio de Urología, Departamento de Urología Pediátrica, Hospital Universitario La Fe, Valencia, España

*Autor para correspondencia.

Correo electrónico: joseantoniomarch@hotmail.com

(J.A. March Villalba).

\section{Nefroma multilocular quístico. Nuevo caso y revisión de la literatura médica reciente}

\section{Cystic nephroma. Case report and overview of recent literature}

\section{Sr. Director:}

Presentamos el caso de una mujer de 52 años de edad, sin antecedentes familiares o personales de interés, salvo perimenopausia. En noviembre de 2007 consulta por molestias difusas y leves en el hemiabdomen izquierdo, con pirosis y sensación de distensión abdominal alta. Se realiza una ecografía abdominal, que revela una masa retroperitoneal mixta, solidoquística, de $20 \times 13 \times 16 \mathrm{~cm}$, que contacta con la cola del páncreas y desplaza el riñón izquierdo hacia atrás. Análisis de sangre y de orina dentro de la normalidad. Radiografía de tórax normal. Tomografía computarizada: masa renal izquierda de $13 \times 19 \times 13 \mathrm{~cm}$, multiquística, bien delimitada y con discreta calcificación lineal periférica focal. Múltiples septos realzantes. No presenta adenopatías ni lesiones sugestivas de metástasis. El resto del abdomen sin datos de interés (fig. 1).

Se realiza nefrectomía simple izquierda (26-11-2007) con la sospecha de probable nefroma quístico (CN) y menos probablemente carcinoma renal quístico. Postoperatorio sin incidencias.

La pieza de nefrectomía izquierda, de $2.490 \mathrm{~g}$, muestra una lesión redondeada que mide $18,5 \times 15 \mathrm{~cm}$, bien delimitada, no encapsulada, que desplaza el parénquima renal normal, del que sólo se identifican dos pequeñas porciones de aspecto normal correspondientes a ambos polos. La lesión tiene aspecto poliquístico, con contenido seroso y de consistencia esponjosa. El estudio histológico (fig. 2) demuestra que los quistes se encuentran revestidos por una única capa de células aplanadas o cuboidales, carentes de atipia. El citoplasma es levemente acidófilo, sin características peculiares. Entre los quistes se aprecia estroma moderadamente celular, formado por células fusiformes, de núcleos ovalados, regulares, igualmente carentes de atipia. En ocasiones, es evidente la diferenciación muscular lisa. No se observan elementos blastematosos. El estudio inmunohistoquímico revela positividad en las células epiteliales para diferentes tipos de citoqueratina (5-6, 7, 34-beta-E12, 18 y 19), pero no para citoqueratina 20. Por su parte, el estroma se tiñe con vimentina, actina de músculo liso $\mathrm{y}$, focalmente, con desmina. Los receptores de estrógenos y progesterona son positivos en la mayor parte de las células estromales. La tinción con CD 10 resultó completamente negativa.

Las diferentes formas de entender el concepto «quístico» (anatomopatológico o radiológico) en las masas renales han llevado a una enorme confusión terminológica y conceptual muy poco clarificadoras, pero acertadamente valoradas en la reciente literatura médica nacional ${ }^{1}$ por lo que el término de 